\title{
Use of the fatigue index to study rolling contact wear
}

\author{
Fidel Salas Vicente ${ }^{1, *}$, Manuel Pascual Guillamón ${ }^{1}$ \\ ${ }^{a}$ Mechanical and Materials Engineering Department, Universitat Politècnica de València, \\ Camino de Vera s/n, 46022, Valencia, Spain.
}

\begin{abstract}
Although both wear and fatigue are inevitably associated with the wheel/rail contact, they are normally studied as different phenomena and both are commonly considered excluding. Wear of railway wheels and rails is usually studied by relating wear rate to the $T \gamma$ or $T \gamma / A$ parameters or by plotting the so called "wear maps", where different rolling parameters are related to the wear rate. On the other hand, fatigue in wheel/rail contact is mainly studied from the surface and subsurface stress or deformation fields and from the crack growth rate.

However, one of the main causes of wear in rolling contact is the loss of material due to delamination processes that have their origin in the presence of surface fatigue cracks. So, if wear and fatigue are related, it should be possible to study both of them using the same method.

In this paper, the fatigue index, based on the shakedown theory and used to predict the surface initiated fatigue of railway wheels, is proposed as a means to study the wear rate in rolling contact. The fatigue index is directly related to the apparition and growth of fatigue cracks at the surface and, thus, directly related to the peeling and spalling processes that constitute the severe and catastrophic wear mechanisms.

The data collected from a series of twin-disc tests show that the wear rate correlates with the fatigue index following an exponential evolution independently of the normal load. Furthermore, a fatigue index around 0 marks the onset of severe wear.
\end{abstract}

Keywords: Wear, fatigue index, rolling contact, peeling

\footnotetext{
${ }^{*}$ Corresponding author

Email addresses: fisavi@doctor.upv.es (Fidel Salas Vicente), mpascual@mcm.upv.es (Manuel Pascual Guillamón)
} 


\section{Introduction}

The study of rolling contact wear remains a matter of interest for both researchers and industry, mainly due to the difficulty of dealing with the huge range of variables that influences the transmission of forces between the train and the track or the wear rates of wheels and rails. Creepage (linear speed difference between wheel and rail divided by the mean velocity), but also normal load, speed of the vehicle, presence of contaminants or water on track, contact geometry, or the characteristics of the materials in contact are some of the most important.

Such a great group of influencing factors represents a difficulty to obtain universally valid data from rolling contact tests [1]. Leaving aside numerical simulations, small Amsler or twin-discs machines are perhaps the more common means of studying the wheel/rail pair behaviour due to their relative low cost and the good control they provide over the variables of interest, especially if good practices, as the ones described in [2] by Lewis, are followed. In these machines, two small discs are pressed against each other while are forced to rotate in opposite directions with a fixed percent slip, which is obtained using slightly different rotating speeds for each disc, while tangential and normal loads are measured.

Wear is not directly related to the normal load applied in the tests, but to the shear stress at the contact and the slip. It is usually studied through the use of wear regimes: mild, severe and catastrophic (figure 1), mainly using the parameters $T \gamma[3-5]$ or $T \gamma / A$ [6-9], where $\mathrm{T}$ is the tangential force, $\gamma$ the slip and A the contact area. Other authors prefer the use of wear maps, where the wear rate depends on the combination of two parameters (e.g. contact pressure and sliding velocity) $[10,11]$.

The other common phenomenon that reduces the life of wheels and rails is fatigue. Fatigue is usually studied as a different process than wear and both are considered to be in constant competition because if the removal of material due to wear is faster that the growth rate of cracks, they can be totally removed or, at least, they can not reach a critical length [12-14]. So, wear can avoid a fatigue failure, but when the classic wear mechanisms (abrasive, oxidative and adhesive) can not avoid the growth of cracks, other wear mechanisms that lead to the apparition of pits on the surface can appear (figure 2): peeling, spalling and "fatigue wear" [15], all of them driven by 


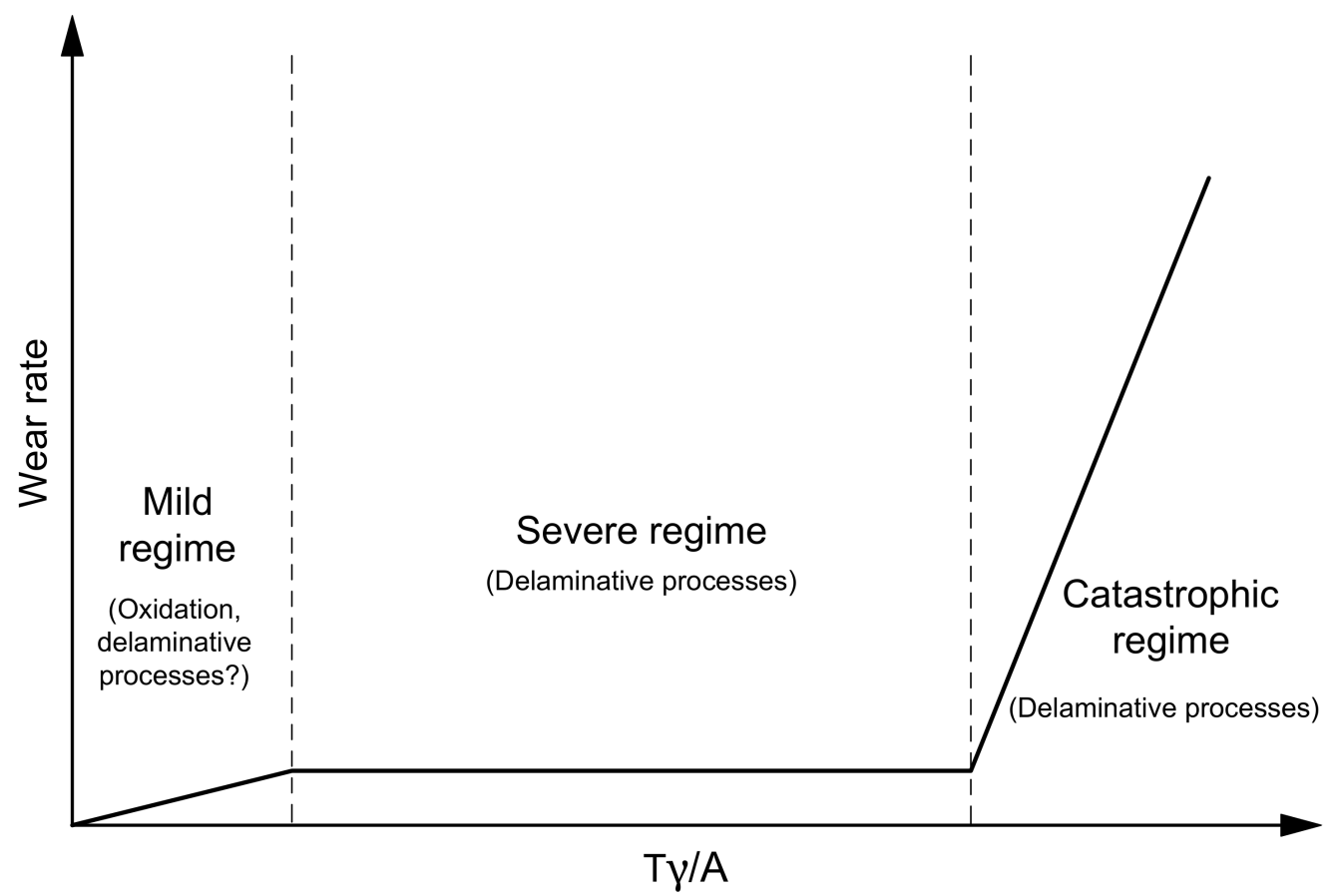

Figure 1: Wear regimes and mechanisms 
the nucleation and growth of cracks. In this case, wear and fatigue are the same phenomenon or, at least, they have the same origin [16]. Evidently, the chance of a crack growing deep into the material exists (the term "rolling contact fatigue" is usually reserved for this situation).

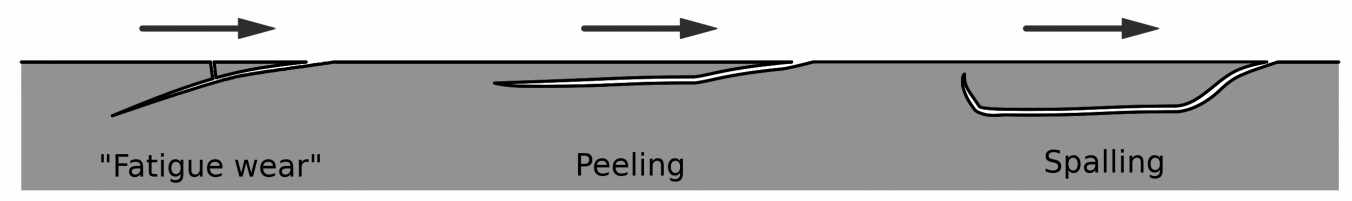

Figure 2: Fatigue-related wear mechanisms. From [15]

Of the three wear regimes, the mild one is mainly related to oxidation and the other two, severe and catastrophic, to delaminative processes $[11,17]$ like the ones described in figure 2, although some authors also relate mild wear to delamination [15]. As those wear mechanisms are eventually driven by the unidirectional cyclic accumulation of plastic deformation (ratcheting) that takes place at the surface of wheels and rails and ultimately leads to crack initiation and growth [18-21], it is plausible that a ratchetting or fatigue related parameter could be used to study fatigue-driven wear.

In the present study, the fatigue index FI [22], a parameter based on the shakedown theory and used to predict the surface initiated fatigue of railway wheels, is proposed as a means to relate wear with the contact conditions (normal pressure and slip) and material properties.

In order to assess the possible relationship between wear rate and the fatigue index FI, a battery of twin-disc tests was carried out using a wide range of normal load and creepage combinations. These are not the only variables influencing wear, but perhaps they are, along with train speed and track contamination, the most important ones. The obtained wear rates were plotted against the fatigue index and fitted to a mathematical function.

\section{Experimental details}

\subsection{Test machine}

The tests were performed with a twin-disc machine whose design is based on the "SUROS" machine [23] of The University of Sheffield. A schematic representation of the machine can be seen in figure 3. It uses two identical 
motors of $2905 \mathrm{rpm}$ and $3 \mathrm{~kW}$. Each one of the motors is coupled to a gearbox, so that the nominal torque is $65 \mathrm{Nm}$ and the output speed $416 \mathrm{rpm}$, very close to the speed used by other authors with similar size of discs [23-25]. Two frequency converters (ABB model ACS355) control the speed of each motor and thus, the slip ratio that appears at the contact between the two twin discs. One of the shafts has a torque transducer (HBM model T20WN$100 \mathrm{NM}$ ) between two flexible joints and the other one has a double cardan joint that joins the shaft with a sliding table. This table allows the two drive shafts to remain parallel even in the case of high wear rates and a loss of geometry and facilitates the unmounting of the discs.

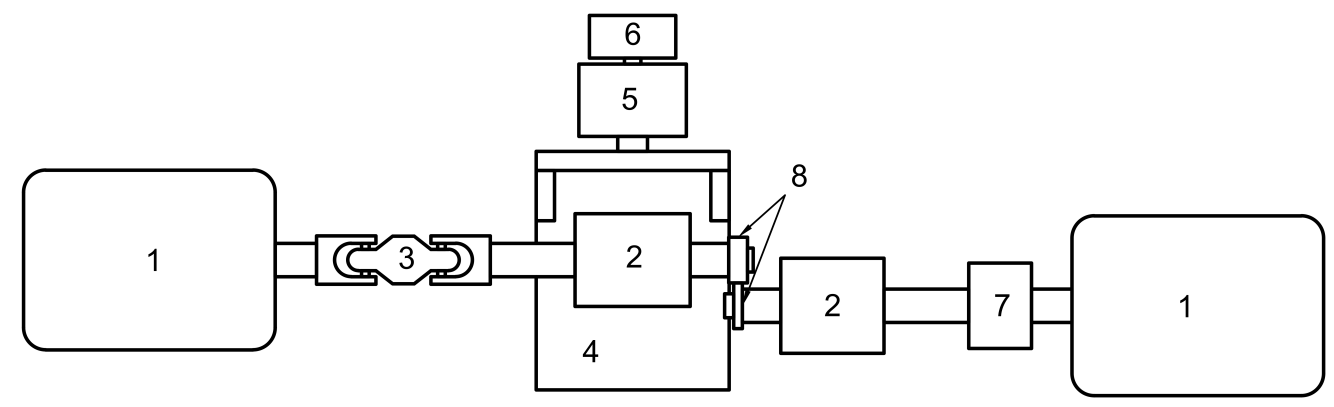

Figure 3: Scheme of the twin-disc test machine. 1: Servomotors; 2: Bearings; 3: Double cardan joint; 4: Sliding table; 5: Hydraulic cylinder; 6: Load cell; 7: Torque and rotational speed transducer; 8: Test discs.

The application of the normal force is made by means of a hydraulic cylinder (Enerpac BD18202) with a capacity $17 \mathrm{kN}$. This cylinder is leaning against a load cell (HBM RTN 2.2) with a capacity of 2.2 Ton, which measures the applied normal force. The pressure needed by the cylinder is obtained from a regulated hydraulic compressor.

Normal load, torque and speed values were acquired at a frequency of 4 $\mathrm{Hz}$ by means of a National Instruments USB-6210 data acquisition system.

\section{2. specimens}

It is a common practice when working with twin-disc machines to cut the discs from actual rails and wheels. This gives the researcher the possibility to work with the same steels that are used in the railway industry. Despite the high cost of machining the amount of discs that sometimes is required, when evaluating the behaviour of a particular combination of rail and wheel 
steels no other option should be considered. This changes when the object of study is the rolling contact phenomenon itself. In those cases, the use of discs machined from plain carbon steels rods could reduce the needed investment if results are not altered significantly. Although a minority, some authors have chosen this approach in the study of rolling contact [26-28] with acceptable results.

In fact, the composition of railway steels is similar to that of plain carbon steels (see table 1) and they could be considered optimized versions of medium or high carbon content steels.

\begin{tabular}{|c|c|c|c|c|c|c|c|c|c|c|c|c|c|}
\hline \multicolumn{14}{|c|}{ Maximum content in wheel steels (\%) } \\
\hline Standard & Grade & $\mathrm{C}$ & $\mathrm{Si}$ & $\mathrm{Mn}$ & $\mathrm{P}$ & $\mathrm{S}$ & $\mathrm{Cr}$ & $\mathrm{Cu}$ & Mo & $\mathrm{Ni}$ & V & $\mathrm{Cr}+\mathrm{Mo}+\mathrm{Ni}$ & $\mathrm{H}^{\hat{*}}$ \\
\hline EN13262 & ER6 & 0.48 & 0.4 & 0.75 & 0.02 & 0.015 & 0.3 & 0.3 & 0.08 & 0.3 & 0.06 & 0.5 & $2 / 2.5$ \\
\hline JIS E5402 & $\mathrm{C} 44$ & 0.46 & 0.4 & 0.9 & 0.04 & 0.04 & 0.3 & 0.3 & 0.08 & 0.3 & 0.05 & - & - \\
\hline GOST 10791 & 1 & $0.45 / 0.52$ & $0.4 / 0.65$ & $0.8 / 1.2$ & 0.035 & 0.03 & 0.3 & 0.3 & 0.08 & 0.3 & 0.15 & - & 2 \\
\hline IRSS & R19 & 0.52 & $0.15 / 0.4$ & $0.6 / 0.8$ & 0.03 & 0.3 & 0.25 & 0.28 & 0.06 & 0.25 & 0.05 & 0.5 & 3 \\
\hline \multicolumn{14}{|c|}{ Maximum content in rail steels $(\%)$} \\
\hline UIC $860-0$ & 700 & $0.4 / 0.6$ & 0.35 & $0.8 / 1.25$ & 0.05 & 0.05 & - & - & - & - & - & - & - \\
\hline EN 13674 & $\mathrm{R} 200$ & $0.4 / 0.6$ & 0.58 & $0.7 / 1.2$ & 0.025 & 0.025 & - & - & - & - & - & - & 3 \\
\hline BS11 1965 & $\mathrm{~B}$ & $0.55 / 0.75$ & 0.5 & $1.3 / 1.7$ & 0.4 & 0.4 & - & - & - & - & - & - & - \\
\hline IRS & 880 & $0.6 / 0.8$ & 0.5 & $0.8 / 1.3$ & 0.025 & 0.025 & $0.3 / 0.8$ & - & - & - & - & - & 3 \\
\hline \multicolumn{14}{|c|}{ Composition of the used carbon steels (\%) } \\
\hline EN $10083-2$ & $\mathrm{C} 45 \mathrm{E}$ & 0.45 & 0.21 & 0.68 & 0.018 & 0.024 & 0.11 & 0.022 & 0.010 & 0.06 & - & 0.18 & - \\
\hline EN 10083-2 & C55E & 0.55 & 0.37 & 0.74 & 0.006 & 0.028 & 0.11 & 0.023 & 0.003 & 0.02 & - & 0.13 & - \\
\hline
\end{tabular}

Table 1: Composition of some railway steels with low carbon content and the two plain carbon steels used in this study.

It can be alleged that the metallurgical differences between plain carbon steels and railway steels are excessive. Walther [29] states that, due to heat treatment of wheels, microstructural gradients occur and thus, its characteristics can not be compared to test samples made of more common carbon steels despite having similar compositions. Nevertheless, it must be also considered that if the change of mechanical properties with depth prevents the use of non-railway steels, something similar could be said about test samples obtained from wheels and rails if they are not heat treated after machining to accurately reproduce the original gradient of properties, even when they are machined parallel to the surface as recommended by Lewis [2] to reduce this problem to a minimum. Evidently, that is not the case and it has been commonly accepted that tests with discs cut from actual pieces without any additional treatment are acceptable.

Assuming the differences are low enough to consider carbon steels valid candidates in the study of wheel-rail contact when non demanding studies are considered, the test discs were machined from C45E (wheel discs) and C55E 
(rail discs) bars. Apart from having a similar chemical composition than ER6 and R200 steels (table 1) some other characteristics are also similar. E.g., if the equivalent carbon content $\mathrm{CE}$, one parameter used to measure the hardenability of a steel, is calculated for each steel using the Dearden and O'Neill formula [30], the C45E steel $(\mathrm{CE}=0.60)$ complies with the $\mathrm{CE}$ maximum value calculated for the ER6 steel $(\mathrm{CE}<0.73)$ and the $\mathrm{C} 55 \mathrm{E}$ steel carbon content $(\mathrm{CE}=0.70)$ falls within the range calculated for the $\mathrm{R} 200$ steel $(0.49<\mathrm{CE}<0.86)$. This does not mean that the results are directly comparable with those obtained if ER6 and R200 steels grades were used as there are other important differences like the higher mechanical properties of the rail and wheel steels and the aforementioned heat treatments.

$$
C E=\% C+\frac{\% M n}{6}+\frac{\% C r+\% M o+\% V}{5}+\frac{\% N i+\% C u}{15}
$$

Both discs had a diameter of $35 \mathrm{~mm}$, but the wheel disc had a width of 15 $\mathrm{mm}$ and the rail disc of $8 \mathrm{~mm}$, thus, the line contact had a length of $8 \mathrm{~mm}$. In order to obtain the lowest possible machining cost while facilitating their mounting and unmounting the discs were machined with a circular keyway. The assembly of the discs can be seen in figure 4 . One or more smaller discs are used to adjust the position on the discs along the end part of the shafts. A last disc plus a bolt act as a lock nut.

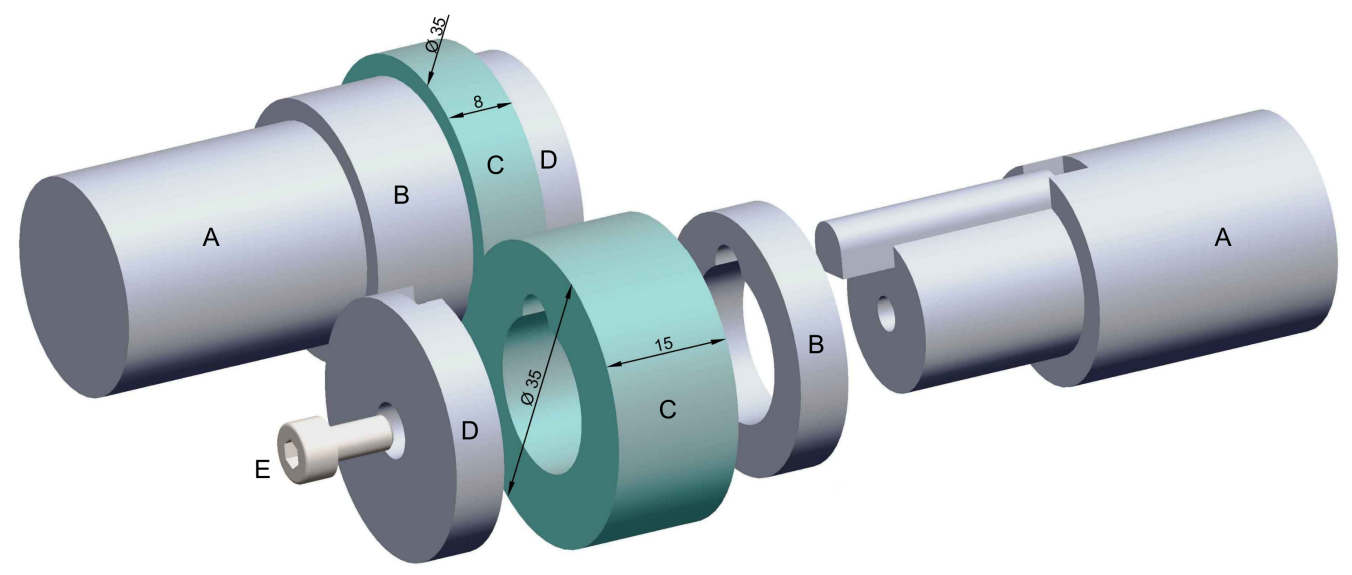

Figure 4: Discs assembly. A: Shafts, B: positioning discs, C: test discs, D: washer discs, E: bolts

The contact surface was polished using sandpaper to a roughness of Ra $\approx 1$ $\mu \mathrm{m}$, similar to the value used by other authors [31, 32], which is typical of 
wheel and rail roughness in some countries [2]. Before each test the discs were degreased using acetone so as to remove any debris or grease that could remain at the surface.

\subsection{Experimental procedure}

Normal pressure and slip were the variables selected to design the tests. The combination of the values selected for these variables led to table 2 , where the characteristics of the conducted tests can be obtained combining the various parameters. One test was carried out in dry condition for each combination of the variables.

\begin{tabular}{|c|c|}
\hline $\begin{array}{c}\text { Max. load pressure (MPa) } \\
{[\text { Normalforce }(N)]}\end{array}$ & Slip \\
\hline $688.5[925.6]$ & $0.10 \%$ \\
\hline $918.0[1645.6]$ & $0.25 \%$ \\
\hline $1147.5[2571.2]$ & $0.50 \%$ \\
\hline $1383.7[3738.4]$ & $0.50 \%$ \\
\hline & $0.75 \%$ \\
\hline & $1.00 \%$ \\
\hline & $2.00 \%$ \\
\hline & $5.00 \%$ \\
\hline
\end{tabular}

Table 2: Values of the parameters selected for the twin-discs tests

The selected maximum normal pressures were actually 900, 1200, 1500 and $1800 \mathrm{MPa}$, but as the mechanical characteristics of the used steels are inferior to that of the equivalent railway steels, these pressures were corrected according to equation 2, where $\sigma_{Y}$ is the yield strength and $\mathrm{P}_{\mathrm{Nmax}}$ the maximum normal stress. This correction is based on the existing relation between the rolling contact fatigue and the normalized contact pressure [33].

$$
\frac{P_{N \max }^{\prime}}{\sigma_{Y}^{\prime}}=\frac{P_{N \max }}{\sigma_{Y}}
$$

For the ER6 the minimum value of the yield strength according to EN13262 is $500 \mathrm{MPa}$, while according to the certificate of conformity provided by the supplier the yield strength of the C45E was $382.5 \mathrm{MPa}\left(\frac{P_{N \max }}{\sigma_{Y}}=1.8\right)$. The introduction of these values in equation 2 gives the values of table 2 . 
The same calculations can not be carried out for the rail steel as no yield strength is given in the EN 13647-1 standard for the R200 steel.

The applied normal load $\mathrm{F}_{\mathrm{N}}$ was calculated from the maximum normal pressure $P_{N \max }$ according to equation 3 , where $\mathrm{E}$ is the Young modulus, $v$ the Poisson's ratio, a the contact length and $\mathrm{R}$ the radius of the discs [9]. This formula, based on the Hertz theory, is valid for two cylinders of the same diameter, Poisson's ratio and Young modulus.

$$
P_{N \max }=\sqrt{\frac{F_{N} E}{a \pi\left(1-v^{2}\right) R}}
$$

During the tests the rail disc rotated at $416 \mathrm{rpm}$, while the rotation speed of the wheel disc was increased by means of the frequency converter in order to obtain the desired slip. They were stopped after 2750 metres, what accounts for, approximately, 1 hour.

Wear was measured as the difference between the initial and final weight of the discs divided by the nominal contact area $\mathrm{A}$ and the metres covered by the rail disc, always after having cleaned them with alcohol and a soft brush to eliminate the wear particles adhered to its surface. The nominal contact area A was estimated from the normal load using equation 4, that corresponds to the longitudinal hertzian contact area between two identical cylinders.

$$
A=4 a \sqrt{\frac{2 F_{N} R}{\pi a E^{*}}}
$$

where $\mathrm{a}$ is the contact length, $\mathrm{F}_{\mathrm{N}}$ the normal load, $\mathrm{R}$ the reduced radio and $\mathrm{E}^{*}$ the contact modulus:

$$
\begin{gathered}
\frac{1}{R}=\frac{1}{R_{1}}+\frac{1}{R_{2}} \\
\frac{1}{E^{*}}=\frac{1}{2}\left(\frac{1-v_{1}^{2}}{E_{1}}+\frac{1-v_{2}^{2}}{E_{2}}\right)
\end{gathered}
$$

In equation $6, v_{i}$ and $\mathrm{E}_{\mathrm{i}}$ are the Poisson's ratios and the Young modulus of each material respectively. 


\section{Results}

An example of the evolution of the friction coefficient along the tests is presented in figure 5: As can be seen, stabilization requires some time.

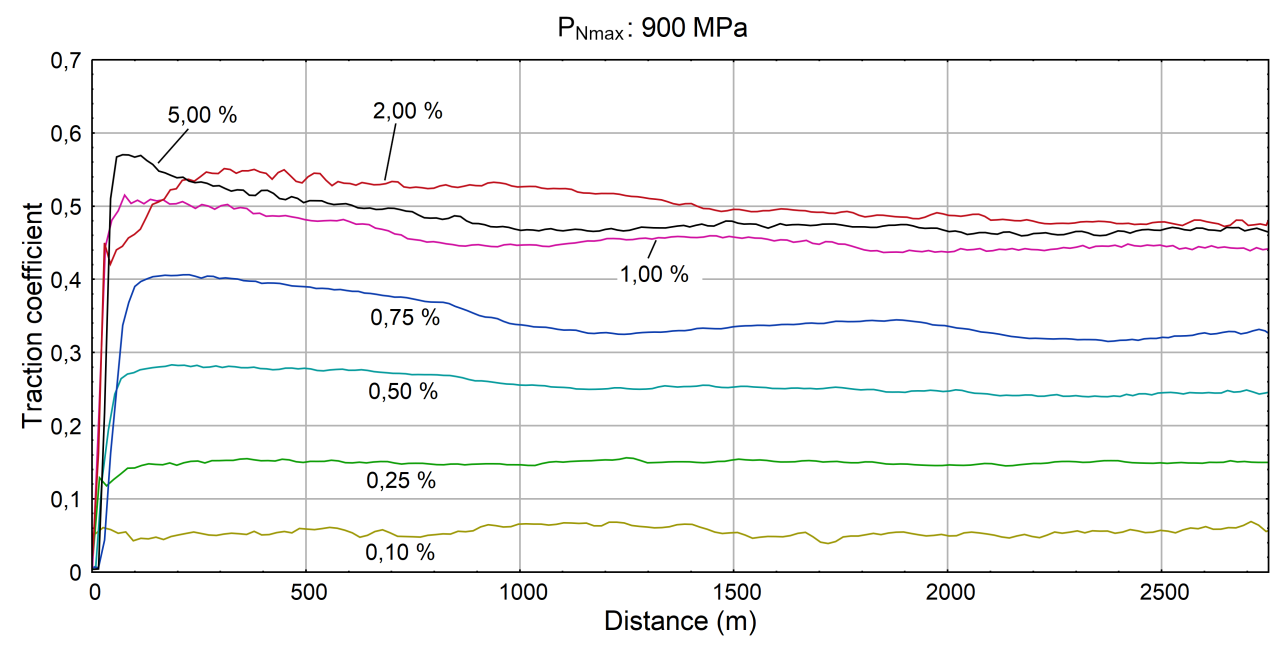

Figure 5: Evolution of the traction coefficient with distance for one of the test batches $\left(\mathrm{P}_{\mathrm{Nmax}}=918,0 \mathrm{MPa}\right)$

Traction coefficients are shown in figure 6 . Their value was taken at 10000 revolutions, as at that point the value of the traction coefficient was considered a value more representative of the whole test than the maximum traction coefficient or the final one. As can be seen in that figure, the adherence decreases as normal load is reduced as in [34]. There are some duplicated points in the graphic. Those corresponds to repetitions of the tests that were carried out in order to assess repeatability. Although only a few of the tests were repeated, the correct evolution of the traction coefficient with slip and of the wear rates with $T \gamma / A$ also gives confidence in the repeatability of the tests.

Figure 7 shows the relation between the wear rate of the tested discs and one of the most used parameters in the study of rolling wear: $T \gamma / A$. Using this parameter wear can be classified into 3 regimes: mild, severe and catastrophic.

According to Lewis $[8,34]$, the severe regime would begin at values of $T \gamma / A$ between 10 and $15 \mathrm{~N} / \mathrm{mm}^{2}$, while catastrophic regime would occur at 


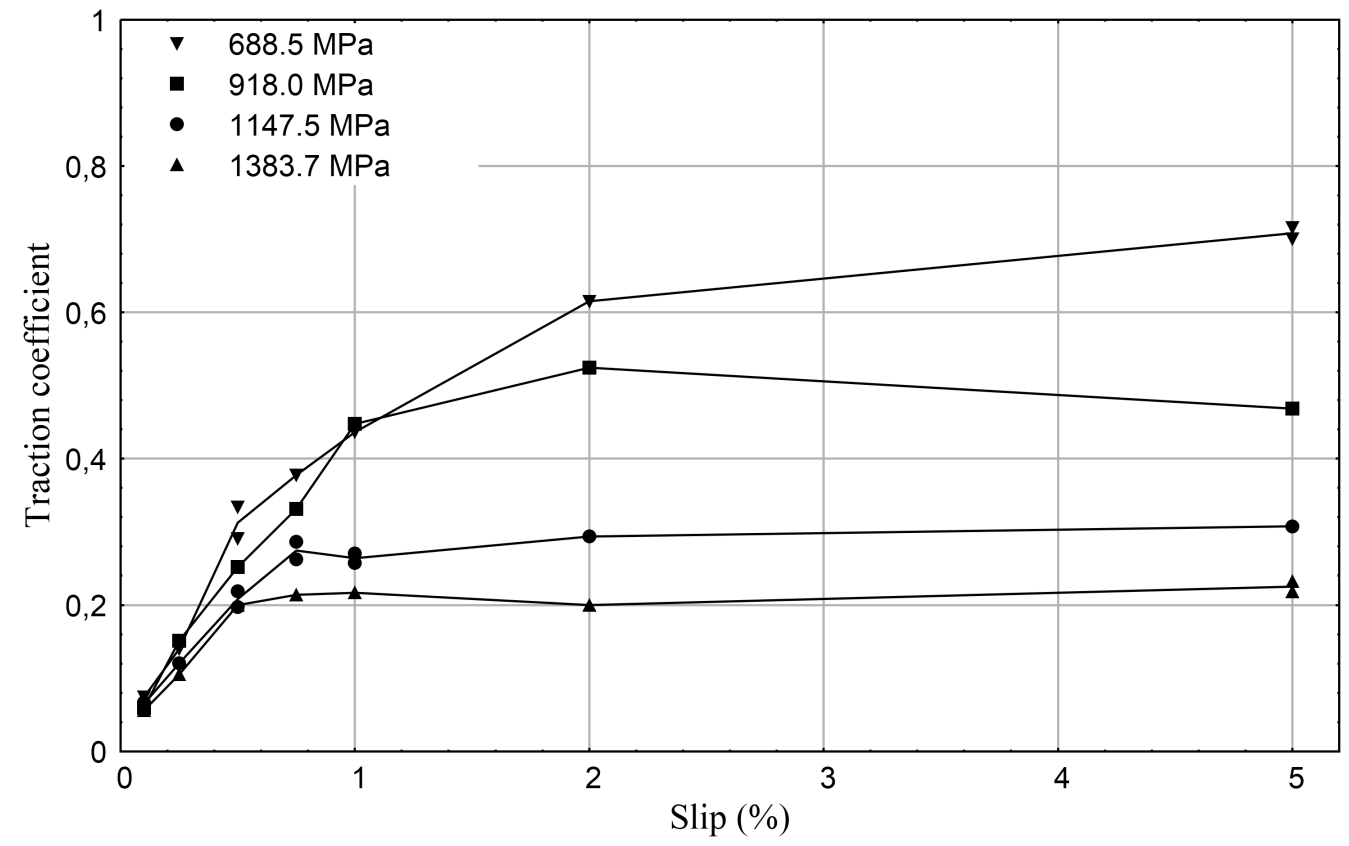

Figure 6: Traction curves 
values of $T \gamma / A$ between 55 and $80 \mathrm{~N} / \mathrm{mm}^{2}$. In the studies carried out by Wang [35] the catastrophic regime begins at $T \gamma / A=25 \mathrm{~N} / \mathrm{mm}^{2}$.

Regardless of the selected points of transition, due to its magnitude, the observed wear rate must be classified as mild except for two points, that were classified as severe.

Regarding the lowest wear rate values, they may not be totally exact because wear does not only take place in the area of contact between the discs, but also on their inner side due to the relative micromovements of fretting between that face and the shaft. Although a layer of grease was applied on the shaft to lubricate and minimize this wear, a certain level of wear, which could affect the measurements of the lowest wear rates (below $0.5 \%$ slip), remained. Unfortunately, it was not possible to evaluate this wear independently.

This low wear rate is related to the fact that the probability of damage by ratchetting, the main phenomenon associated with the appearance of cracks in rolling and therefore, with wear, falls drastically below a coefficient of traction of 0.2 [36].
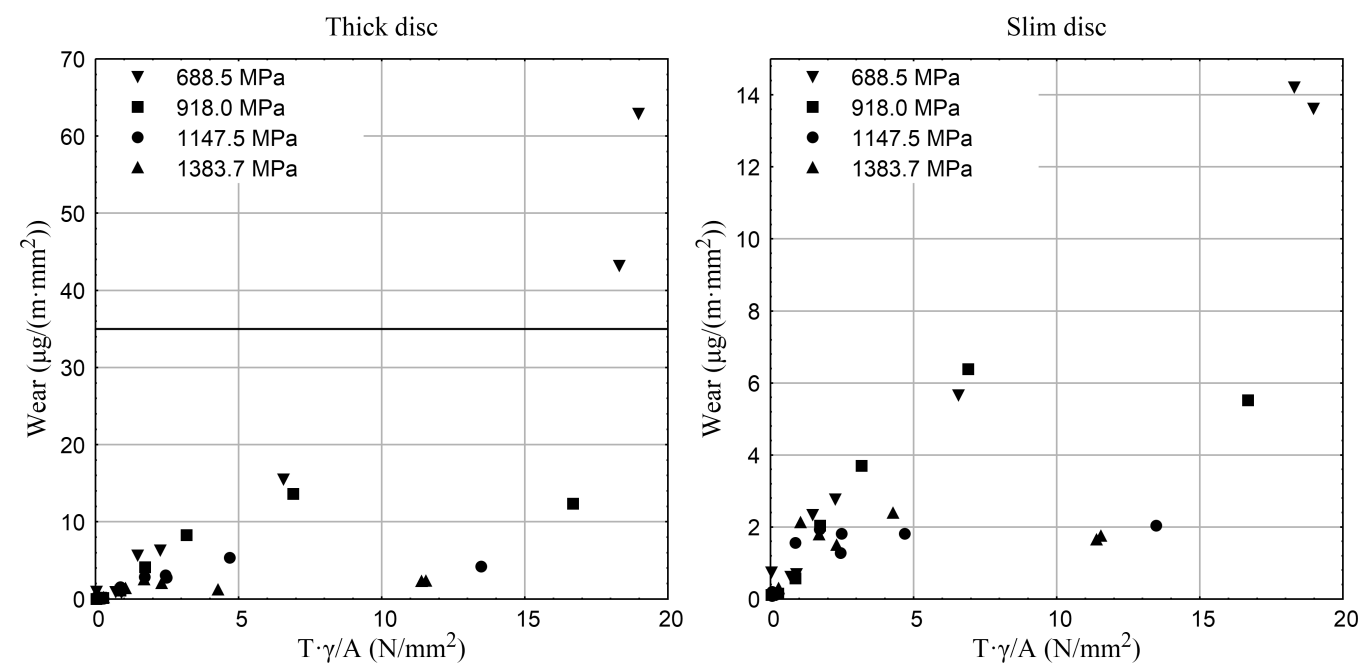

Figure 7: Wear rates of the thick and the slim discs

The highest wear rate is associated with the lowest normal pressure at $5 \%$ slip (beyond $T \gamma / A=18 \mathrm{~N} / \mathrm{mm}^{2}$ ). This apparent contradiction disappears when taking into account that tangential and not normal stresses are the main causes of the plastic deformation that leads to the appearance of surface 
cracks and, finally, to peeling. In the tests the decrease in the value of the traction coefficient when increasing the normal load is of such magnitude that the product of both, the tangential stress, falls (see figure 8). A decrease in the wear rate with an increment in the normal load can also be found in [34] although not in other papers [15].
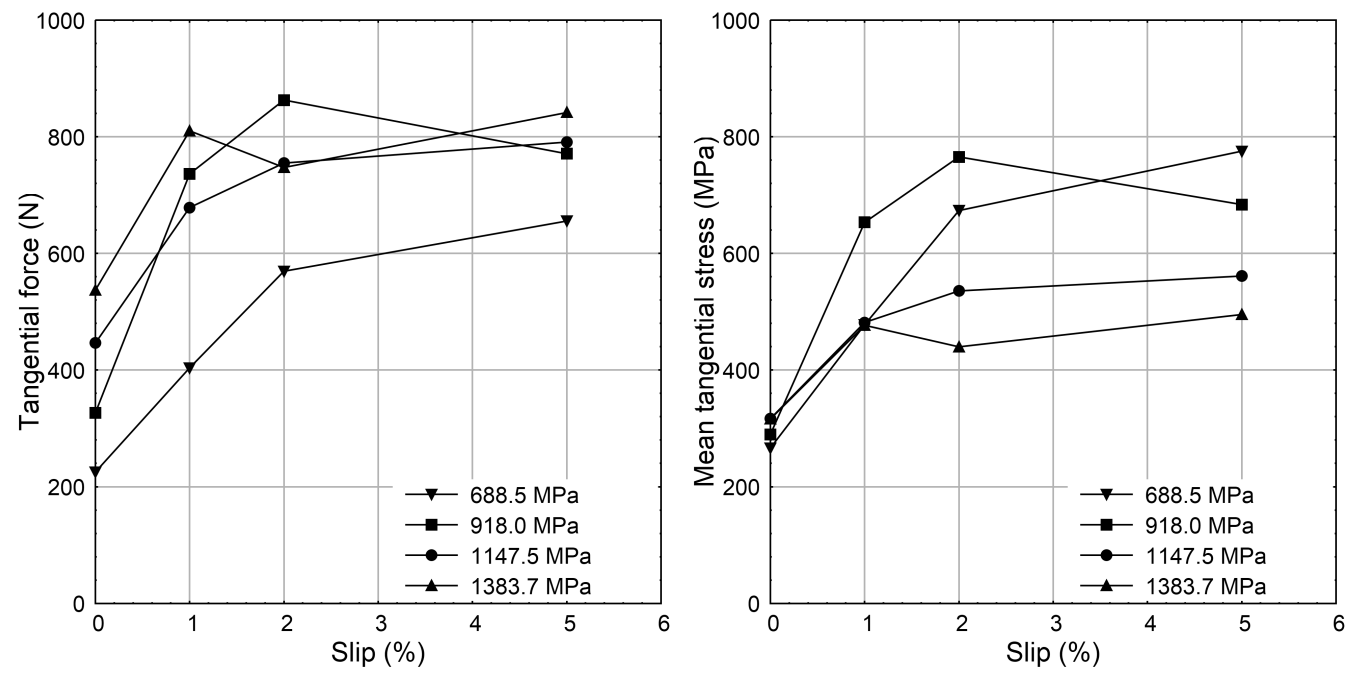

Figure 8: Tangential force and mean tangential stress at the contact

A variable that was not taken into account during the design of the tests is the width of the discs. However, it could to be of great importance as the slim discs adopts, due to wear and plastic deformation, a convex shape and the thick disc a convex shape with a very limited lateral plastic flow. The wear rate of the thick discs reaches higher levels than that of the slim discs. Unfortunately, as the thick discs are machined in C45E steel, which has lower mechanical properties than the C55E steel of the slim discs, the influence of the discs width can not be quantified and tests with both discs machined using the same material are needed.

As expected, cross-section micrographs of the discs show a great amount of plastic deformation (see figure 9). That suggests the main wear mechanism has been the delamination caused by the cracks that appear at the surface due to the accumulation of unidirectional plastic deformation, or ratcheting [37]. This is a fact that can be checked by looking at the photos provided by many authors [38-41] and can also be seen in figure $9 \mathrm{~b}$. Besides the simple apparition of cracks due to ratchetting, three other related phenomena 
increase the wear rate: ferrite lines, adhesion and growth of cracks by plastic deformation.

- Ferrite lines:

Figure 9a shows how the plastic deformation of the surface aligns the ferrite contained in the steel to form white soft ferrite lines. The presence of these lines favours the crack growth due to their lower stress limit [15]. Even if the content in ferrite of the steel is low, the alignment of the lamellar microstructure of the perlite can lead to a higher rate of crack growth compared to the non-deformed microstructure

\section{- Adhesion:}

Another phenomenon that increases the wear rate is the adhesion of the material above the crack on the surface of one disc to the surface of the other disc (in the rest of the paper this material will be called "flake", even if it is still adhered to the disc). After adhering, as the discs continue its rotating movement, the distance between both surfaces increases and the flake is pulled up and backwards. This mechanism involves a faster crack growth and even the possibility of the flake being torn apart from the surface in a peeling process. This process is shown in figure 10 along with the photo of a flake that has been turned backwards.

- Flake elongation:

This process is described in figure 11 and leads to an increase in the crack length that adds to the fatigue growth [42]. In order to simplify, the initial state of the crack could be described by figure 11-a as a semicircular crack front under the surface and a straight crack mouth on the surface. The black arrow indicates the direction of the tangential stress acting on the surface. Although this stress can be supposed to act uniformly on all the crack length, the plastic elongation of the flake near both sides of the crack will be smaller than the elongation at the middle of the crack because the length of unattached material goes from 0 at both ends to a maximum at the middle of the crack mouth. The different elongation of each part of the crack changes its shape, that now has the aspect shown in figure 11-b. In fact, the process is analogous to the rolling of a metal sheet. 


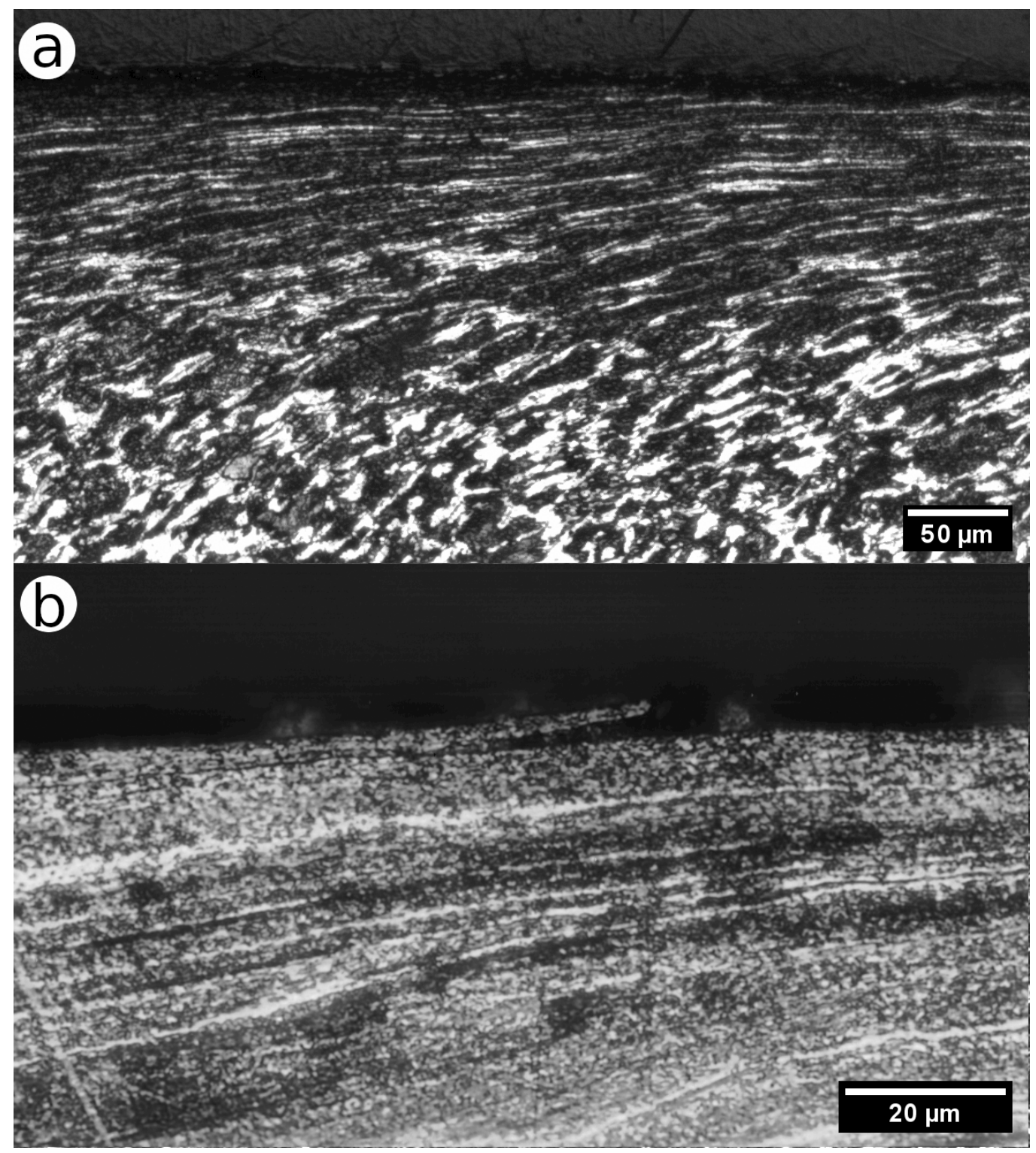

Figure 9: a: Plastic deformation and ferrite lines in a deformed thick discs (5\% slip, $\mathrm{P}_{\mathrm{Nmax}}=1383.4 \mathrm{MPa}$ ). b: Flake at the surface of a tested disc 

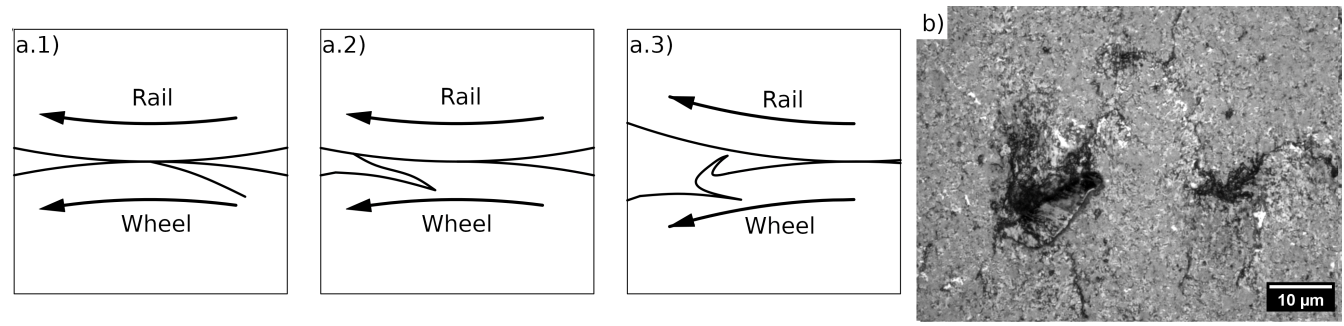

Figure 10: a) Effect of adhesion on a flake. b) Flake pulled backwards due to adhesion (thin disc, $0.75 \%$ slip, $\mathrm{P}_{\mathrm{Nmax}}=1147.5 \mathrm{MPa}$ )
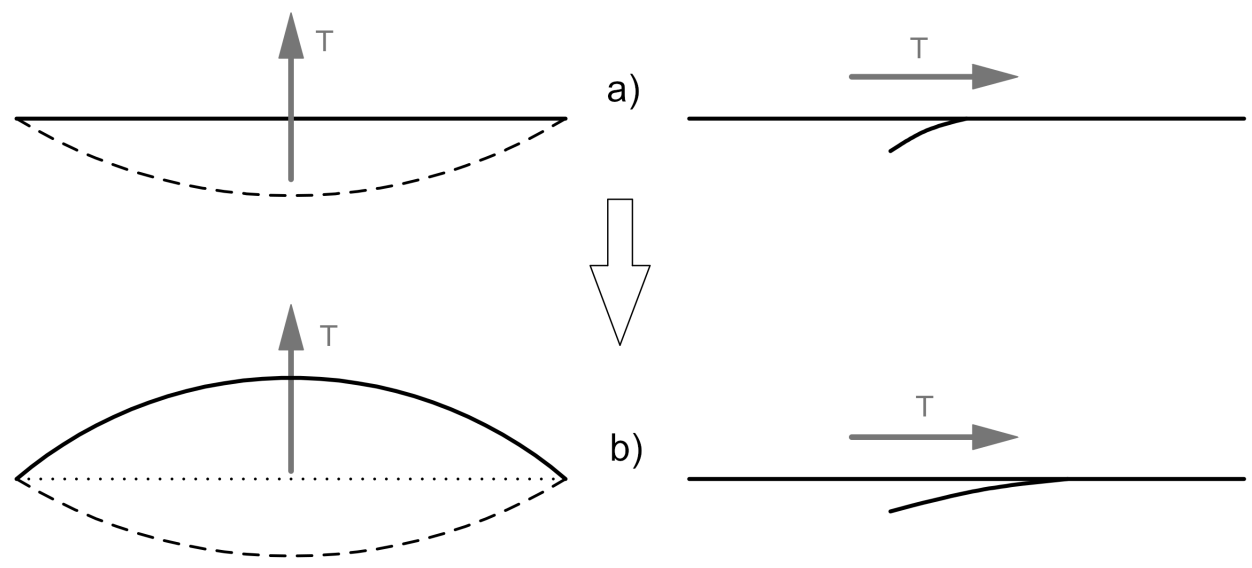

b)

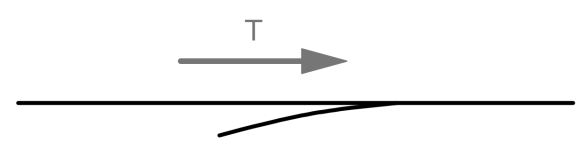

Figure 11: Elongation of flakes due to tangential stress

This behaviour is confirmed by the aspect of some cracks that have peeled (figure 12), with scratches that emanate from the initial crack mouth. These marks were not originated by the fatigue growth of the crack as they are perpendicular and not parallel to the crack front line, but by the described mechanism due to the relative movement of the upper face of the crack over its lower face.

All these wear mechanisms are related to the presence of cracks on the surface and justify that a fatigue related parameter such as the fatigue index, FI, could be used as a means to study wear. This index makes use of the shakedown diagrams (figure 13) to obtain a measure of the load level at the surface and serves to predict the onset of fatigue when $F I \geq 0$. In these diagrams the adhesion coefficient is represented in the $\mathrm{X}$ axis, while the relation between the peak normal pressure and the shear yield strength 


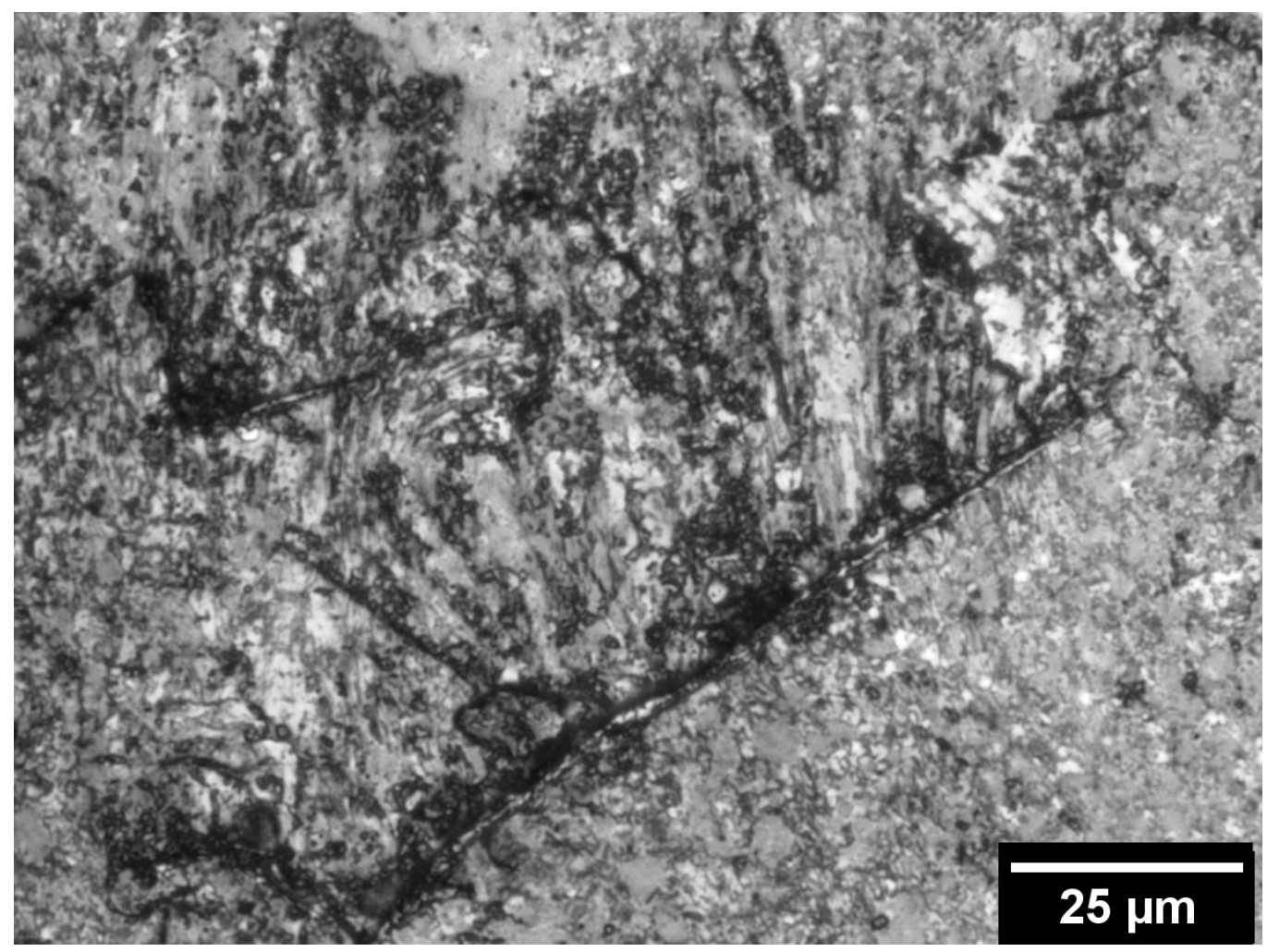

Figure 12: Scratches under an elongated flake after it has been unattached (thin disc, $5 \%$ slip, $\left.\mathrm{P}_{\mathrm{Nmax}}=1383.7 \mathrm{MPa}, \mathrm{x} 400\right)$ 
is represented in the $\mathrm{Y}$ axis. When applied to the surface the fatigue index is the horizontal distance from the work point of the system to the limit of the ratchetting zone, where no continuous incremental growth of plastic deformation occurs. FI is defined as:

$$
F I=\mu-\frac{k}{\lambda P_{N \max }}
$$

where $\mu$ is the utilized friction coefficient, $P_{N \max }$ the hertzian maximum normal pressure, $\lambda$ a load factor dependent on the contact geometry [43] and $k$ the yield strength in pure shear. This parameter includes one of the main mechanical properties of steels and, thus, could be helpful to be used for different steels.

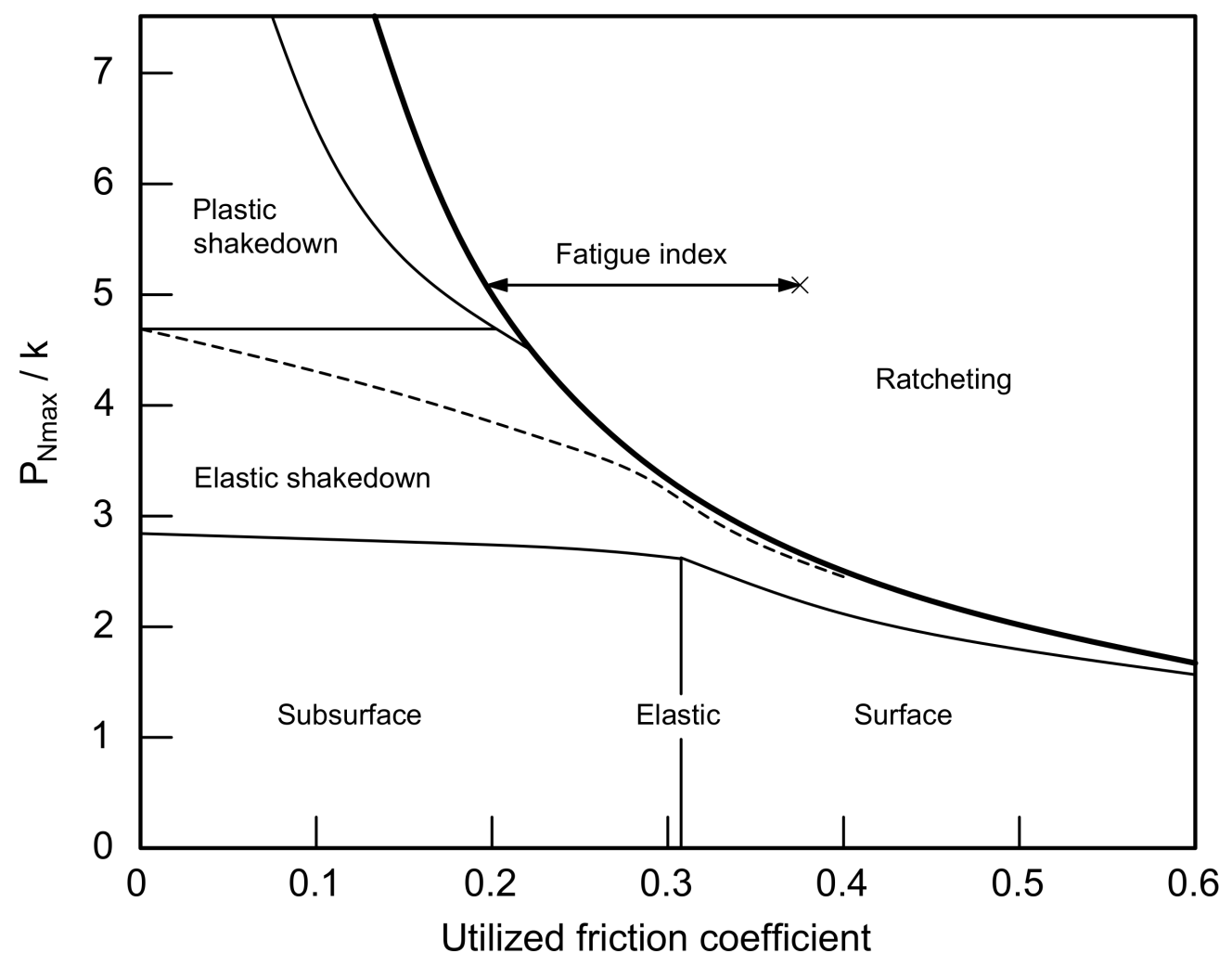

Figure 13: Example of a shakedown map

Figure 14 shows the results obtained by representing the wear rate as a function of the fatigue index when considering $\lambda=1$. As can be seen, FI 
relates quite well with the fatigue-driven wear found in the tests and aligns all the points obtained from the tests at different loads and slips. The best alignement of the points is obtained when the shear yield strength $\mathrm{k}$ was obtained using the Tresca criterion $k=\sigma_{Y} / \sqrt{3}$ (the yield strength was 405 $\mathrm{MPa}$ for the C45E steel and $752 \mathrm{MPa}$ for the C55E steel), while a calculation of $\mathrm{k}$ using the Beltrami theory gave the worse adjustment as produced the highest value of $\mathrm{k}$.
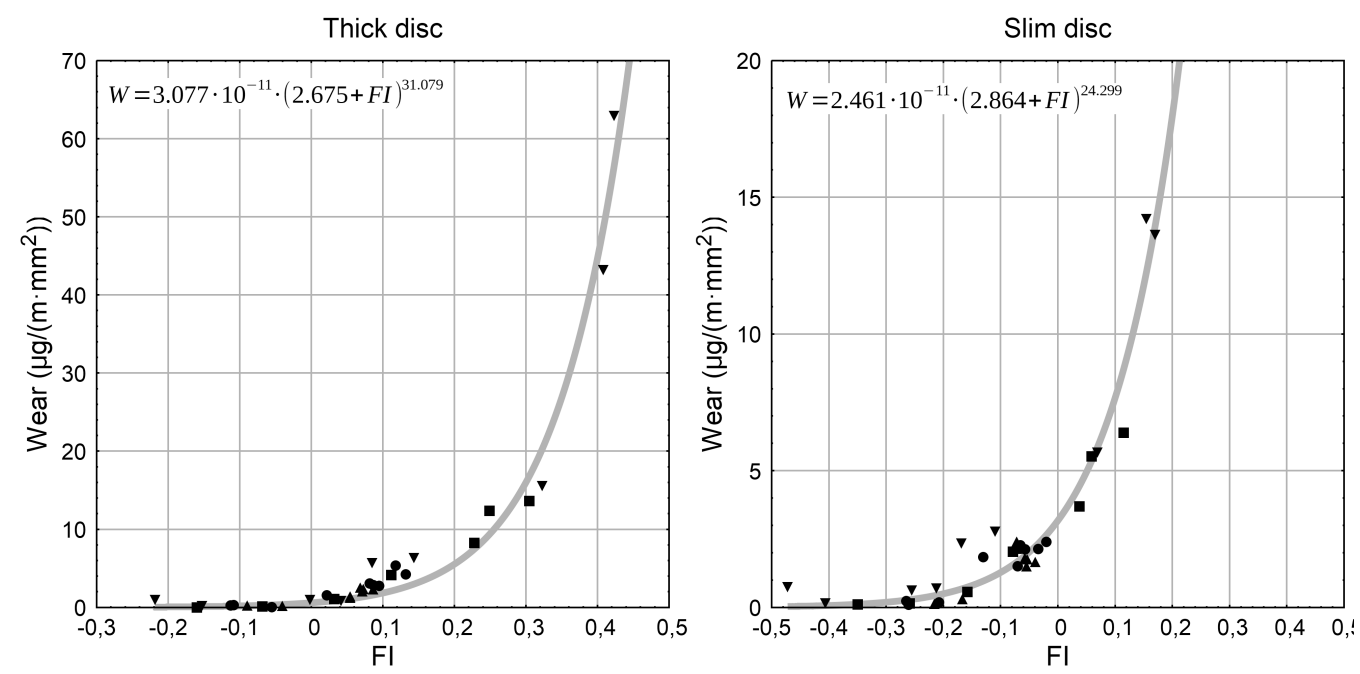

Figure 14: Evolution of the wear rate with the fatigue index for both discs.

Another advantage of the use of FI is that the onset of severe wear corresponds to values of FI near 0 , where it predicts the onset of fatigue. This prediction could, perhaps, be improved with the selection of a different value for $\mathrm{k}$ or the use of a $\lambda$ value different from 1 , but it already shows that the use of the theories developed for fatigue can be used to study rolling contact wear.

A function that adapts quite well, although not perfectly, to the points represented in figure 14 is equation 8 , where $A_{i}$ are the fitting coefficients. The fitted functions are presented in the same figure.

$$
W=A_{1}\left(\frac{A_{2}-F I}{A_{3}}\right)^{A_{4}}
$$

This function does not have any physical meaning, but serves to predict the wear rate in different rolling conditions. 
To further test the possible potential of the use of FI, some wear data was extracted from different published papers, although not many of them give enough data to calculate FI or the wear rate in $\mu \mathrm{g} /\left(\mathrm{m} \cdot \mathrm{mm}^{2}\right)$ and some assumptions had to be done. Figure 15 shows the evolution of the wear rate as FI increases for different combinations of materials and test conditions.
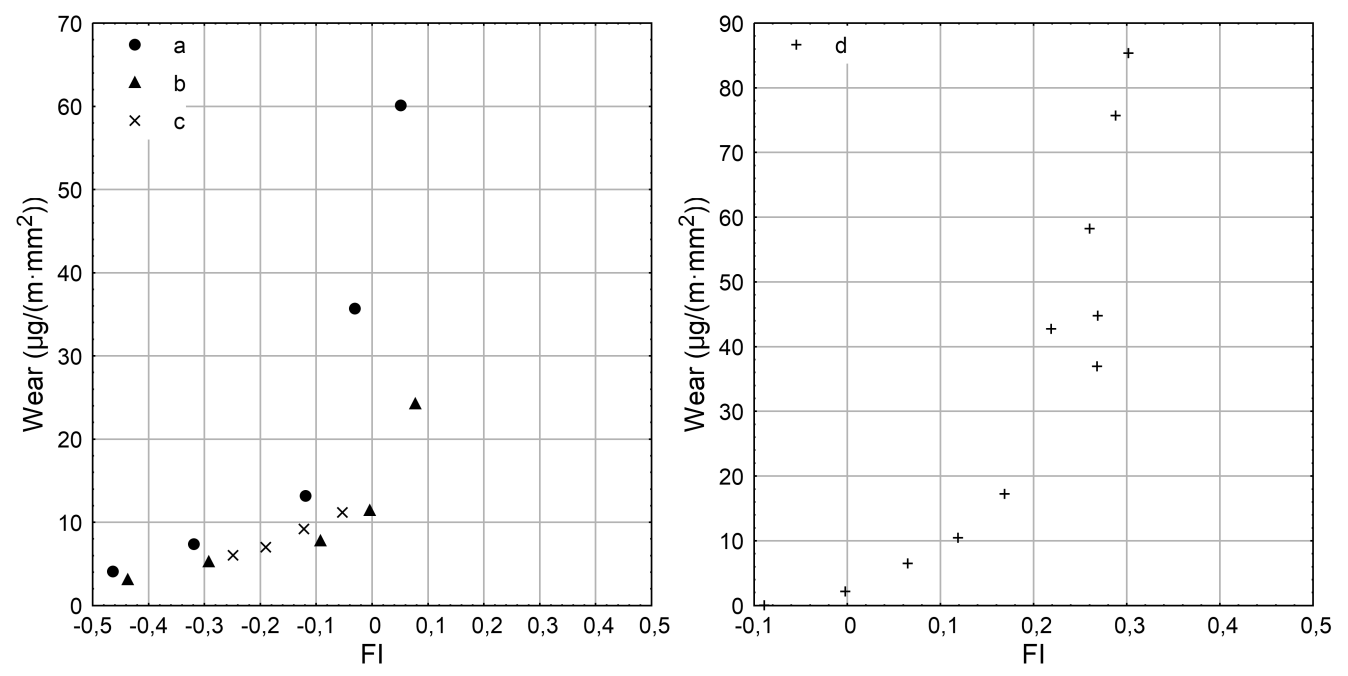

Figure 15: Evolution of the wear rate with the fatigue index for different tests of the bibliography. (a): ER9 steel from [44], (b): U71Mn steel from [44], (c): ER9 steel from [45], (d): R8T steel from [46] and [47].

All the plots show a similar evolution, with a notable change in the wear rate around $\mathrm{FI}=0$. Although the different plots are not aligned, it has to be taken into account that FI has been calculated using $\lambda=1$ for all the tests and the Tresca criterion and not the shear yield strength from actual tests. Furthermore, as the value of the yield strength was not found in the papers, it was estimated using, when available, the minimum value the standards demand from the steels or a value from other papers ([48] for the U71Mn steel). One last but very important problem is that the traction coefficients used to draw figure 15 could be the maximum or the final ones and not one value more representative of the whole test as the one selected in this study, as no information is given about that in the studied papers. 


\section{Conclussions}

Due to the fact that the main mechanisms of wear and fatigue in rolling contact are related to ratchetting and the nucleation and growth of surface fatigue cracks, the use of the fatigue index FI has been proposed as a means to predict the wear rate in rolling contact with interesting results.

The plotting of the wear rates obtained from a series of twin-disc tests against the fatigue index reduces scattering and aligns all the points representing the wear rates, independently of the normal pressure, following an exponential shaped function that could be used to calculate the wear rate. Furthermore, this index predicts a notable increment of the wear rate when it is equal or greater than 0 .

The use of FI has been tested using the wear data for actual wheel and rail steels found in the the bibliography. The evolution of the wear rate with FI shows the same behaviour found with the pair C45E-C55E, although the lack of reliable data for the yield strength and the traction coefficient hinders a better comparison of the wear rates published in those papers with the values presented in this paper.

The use of this parameter or a similar one seems promising as a way to calculate the rolling contact wear rate, relate wear and fatigue and introduce the mechanical properties of the steels in the calculation of the wear rate.

\section{References}

[1] P. Clayton, Tribological aspects of wheel-rail contact: a review of recent experimental research, Wear 191 (1-2) (1996) 170-183 (1996). doi:10.1016/0043-1648(95)06651-9.

[2] R. Lewis, E. Magel, W.-J. Wang, U. Olofsson, S. Lewis, T. Slatter, A. Beagles, Towards a standard approach for the wear testing of wheel and rail materials, Proceedings of the Institution of Mechanical Engineers, Part F: Journal of Rail and Rapid Transit 231 (7) (2017) 760-774 (2017). doi:10.1177/0954409717700531.

[3] I. McEwen, R. Harvey, Full-scale wheel-on-rail wear testing: comparisons with service wear and a developing theoretical predictive method, in: ASLE/ASME Lubrication Conference, 1983 (1983).

[4] N. Tassini, X. Quost, R. Lewis, R. Dwyer-Joyce, C. Ariaudo, N. Kuka, A numerical model of twin disc test arrangement for the evaluation of 
railway wheel wear prediction methods, Wear 268 (5-6) (2010) 660-667 (2010). doi:10.1016/j.wear.2009.11.003.

[5] C. Viafara, M. Castro, J. Velez, A. Toro, Unlubricated sliding wear of pearlitic and bainitic steels, Wear 259 (1-6) (2005) 405-411 (2005). doi:10.1016/j.wear.2005.02.013.

[6] P. Bolton, P. Clayton, Rolling-sliding wear damage in rail and tyre steels, Wear 93 (2) (1984) 145-165 (1984). doi:10.1016/0043-1648(84)90066-8.

[7] T. Pearce, N. Sherratt, Prediction of wheel profile wear, Wear 144 (1-2) (1991) 343-351 (1991). doi:10.1016/0043-1648(91)90025-p.

[8] F. Braghin, R. Lewis, R. Dwyer-Joyce, S. Bruni, A mathematical model to predict railway wheel profile evolution due to wear, Wear 261 (11-12) (2006) 1253-1264 (2006). doi:10.1016/j.wear.2006.03.025.

[9] S. Timoshenko, Theory of elasticity, McGraw-Hill, 1987 (1987).

[10] T. Jendel, Prediction of wheel profile wear - comparisons with field measurements, Wear 253 (1-2) (2002) 89-99 (2002). doi:10.1016/s00431648(02)00087-x.

[11] R. Lewis, U. Olofsson, Mapping rail wear regimes and transitions, Wear 257 (7-8) (2004) 721-729 (2004). doi:10.1016/j.wear.2004.03.019.

[12] J. W. Ringsberg, Shear mode growth of short surfacebreaking RCF cracks, Wear 258 (7-8) (2005) 955-963 (2005). doi:10.1016/j.wear.2004.03.043.

[13] G. Donzella, M. Faccoli, A. Ghidini, A. Mazzù, R. Roberti, The competitive role of wear and RCF in a rail steel, Engineering Fracture Mechanics 72 (2) (2005) 287-308 (2005). doi:10.1016/j.engfracmech.2004.04.011.

[14] S. Cantini, S. Cervello, The competitive role of wear and RCF: Full scale experimental assessment of artificial and natural defects in railway wheel treads, Wear 366-367 (2016) 325-337 (2016). doi:10.1016/j.wear.2016.06.020.

[15] H. Ding, C. He, L. Ma, J. Guo, Q. Liu, W. Wang, Wear mapping and transitions in wheel and rail materials under different contact 
pressure and sliding velocity conditions, Wear 352 (2016) 1-8 (2016). doi:10.1016/j.wear.2016.01.017.

[16] R. Smith, Rolling contact fatigue of rails: what remains to be done, China Railway Science 3 (1) (2002) 1-11 (2002).

[17] H. Ding, Z. Fu, W. Wang, J. Guo, Q. Liu, M. Zhu, Investigation on the effect of rotational speed on rolling wear and damage behaviors of wheel/rail materials, Wear 330-331 (2015) 563-570 (2015). doi:10.1016/j.wear.2014.12.043.

[18] A. Bower, K. Johnson, Plastic flow and shakedown of the rail surface in repeated wheel-rail contact, Wear 144 (1-2) (1991) 1-18 (1991). doi:10.1016/0043-1648(91)90003-d.

[19] C. L. Pun, Q. Kan, P. J. Mutton, G. Kang, W. Yan, An efficient computational approach to evaluate the ratcheting performance of rail steels under cyclic rolling contact in service, International Journal of Mechanical Sciences 101 (2015) 214-226 (2015). doi:10.1016/j.ijmecsci.2015.08.008.

[20] G. Trummer, C. Marte, P. Dietmaier, C. Sommitsch, K. Six, Modeling surface rolling contact fatigue crack initiation taking severe plastic shear deformation into account, Wear 352 (2016) 136-145 (2016). doi:10.1016/j.wear.2016.02.008.

[21] A. C. Athukorala, D. V. De Pellegrin, K. I. Kourousis, A unified material model to predict ratcheting response in head-hardened rail steel due to non-uniform hardness distributions, Tribology International 111 (2017) 26-38 (2017). doi:10.1016/j.triboint.2017.02.018.

[22] A. Ekberg, E. Kabo, H. Andersson, An engineering model for prediction of rolling contact fatigue of railway wheels, Fatigue \& Fracture of Engineering Materials \& Structures 25 (10) (2002) 899-909 (2002). doi:10.1046/j.1460-2695.2002.00535.x.

[23] D. I. Fletcher, J. H. Beynon, Development of a machine for closely controlled rolling contact fatigue and wear testing, Journal of testing and evaluation 28 (4) (2000) 267-275 (2000). doi:10.1520/jte12104j. 
[24] P. Dou, S. Suo, Z. Yang, Y. Li, D. Chen, Ratcheting short crack behavior in medium carbon bainitic back-up roll steel under mild tractive rolling contact, Wear 268 (1-2) (2010) 302-308 (2010). doi:10.1016/j.wear.2009.08.015.

[25] C. Hardwick, R. Lewis, R. Stock, The effects of friction management materials on rail with pre existing rcf surface damage, Wear 384 (2017) 50-60 (2017). doi:10.1016/j.wear.2017.04.016.

[26] Y. Zhu, U. Olofsson, K. Persson, Investigation of factors influencing wheel-rail adhesion using a mini-traction machine, Wear 292 (2012) 218-231 (2012). doi:10.1016/j.wear.2012.05.006.

[27] A. Ramalho, M. Esteves, P. Marta, Friction and wear behaviour of rolling-sliding steel contacts, Wear 302 (1-2) (2013) 1468-1480 (2013). doi:10.1016/j.wear.2012.12.008.

[28] Y. Kimura, M. Sekizawa, A. Nitanai, Wear and fatigue in rolling contact, Wear 253 (1-2) (2002) 9-16 (2002). doi:10.1016/s0043-1648(02)00077-7.

[29] F. Walther, D. Eifler, Local cyclic deformation behavior and microstructure of railway wheel materials, Materials Science and Engineering: A 387 (2004) 481-485 (2004). doi:10.1016/j.msea.2004.05.034.

[30] J. Dearden, H. O'Neill, A guide to the selection and welding of low alloy structural steel, Transactions of the Institute of Welding 3 (1940) 203-214 (1940).

[31] O. Arias-Cuevas, Z. Li, R. Lewis, E. Gallardo-Hernández, Rolling-sliding laboratory tests of friction modifiers in dry and wet wheel/rail contacts, Wear 268 (3) (2010) 543 - 551 (2010). doi:10.1016/j.wear.2009.09.015.

[32] O. Arias-Cuevas, Z. Li, R. Lewis, A laboratory investigation on the influence of the particle size and slip during sanding on the adhesion and wear in the wheel/rail contact, Wear 271 (1) (2011) $14-24$ (2011). doi:10.1016/j.wear.2010.10.050.

[33] P. Clayton, X. Su, Surface initiated fatigue of pearlitic and bainitic steels under water lubricated rolling/sliding contact, Wear 200 (1-2) (1996) 63-73 (1996). doi:10.1016/s0043-1648(96)07250-x. 
[34] R. Lewis, R. S. Dwyer-Joyce, U. Olofsson, J. Pombo, J. Ambrósio, M. Pereira, C. Ariaudo, N. Kuka, Mapping railway wheel material wear mechanisms and transitions, Proceedings of the Institution of Mechanical Engineers, Part F: Journal of Rail and Rapid Transit 224 (3) (2010) 125-137 (2010). doi:10.1243/09544097jrrt328.

[35] W. Wang, R. Lewis, B. Yang, L. Guo, Q. Liu, M. Zhu, Wear and damage transitions of wheel and rail materials under various contact conditions, Wear 362-363 (2016) 146-152 (2016). doi:10.1016/j.wear.2016.05.021.

[36] A. Ekberg, E. Kabo, H. Andersson, Predicting rolling contact fatigue of railway wheels, in: 13th International Wheelset Congress in Rome, Rome, 2001, pp. 17-21 (2001).

[37] J. Bree, Elastic-plastic behaviour of thin tubes subjected to internal pressure and intermittent high-heat fluxes with application to fastnuclear-reactor fuel elements, Journal of Strain Analysis 2 (3) (1967) 226-238 (1967). doi:10.1243/03093247v023226.

[38] C. He, J. Guo, Q. Liu, W. Wang, Experimental investigation on the effect of operating speeds on wear and rolling contact fatigue damage of wheel materials, Wear 364-365 (2016) 257-269 (2016). doi:10.1016/j.wear.2016.08.006.

[39] S. Maya-Johnson, J. F. Santa, A. Toro, Dry and lubricated wear of rail steel under rolling contact fatigue - wear mechanisms and crack growth, Wear 380-381 (2017) 240-250 (2017). doi:10.1016/j.wear.2017.03.025.

[40] F. D. Fischer, W. Daves, R. Pippan, P. Pointner, Some comments on surface cracks in rails, Fatigue and Fracture of Engineering Materials and Structures 29 (11) (2006) 938-948 (2006). doi:10.1111/j.14602695.2006.01051.x.

[41] W. Wang, S. Lewis, R. Lewis, A. Beagles, C. He, Q. Liu, The role of slip ratio in rolling contact fatigue of rail materials under wet conditions, Wear 376-377 (2017) 1892-1900 (apr 2017). doi:10.1016/j.wear.2016.12.049.

[42] A. Kapoor, Wear by plastic ratchetting, Wear 212 (1) (1997) 119-130 (1997). doi:10.1016/S0043-1648(97)00083-5. 
[43] A. Ponter, A. Hearle, K. Johnson, Application of the kinematical shakedown theorem to rolling and sliding point contacts, Journal of the Mechanics and Physics of Solids 33 (4) (1985) 339-362 (1985). doi:10.1016/0022-5096(85)90033-x.

[44] L. Ma, C. He, X. Zhao, J. Guo, Y. Zhu, W. Wang, Q. Liu, X. Jin, Study on wear and rolling contact fatigue behaviors of wheel/rail materials under different slip ratio conditions, Wear 366-367 (2016) 13-26 (2016). doi:10.1016/j.wear.2016.04.028.

[45] C. He, Y. Huang, L. Ma, J. Guo, W. Wang, Q. Liu, M. Zhu, Experimental investigation on the effect of tangential force on wear and rolling contact fatigue behaviors of wheel material, Tribology International 92 (2015) 307-316 (2015). doi:10.1016/j.triboint.2015.07.012.

[46] R. Lewis, R. Dwyer-Joyce, Wear mechanisms and transitions in railway wheel steels, Proc. Instn Mech. Engrs. Part J: Engineering Tribology (2004).

[47] R. Lewis, R. Dwyer-Joyce, U. Olofsson, R. Hallam, Wheel material wear mechanisms and transitions, in: 14th International Wheelset Congress, 2004 (2004).

[48] R. Yang, S. Cao, W. Kang, J. Li, X. Jiang, Mechanism analysis of spalling defect on rail surface under rolling contact conditions, Mathematical Problems in Engineering 2018 (2018) 1-10 (2018). doi:10.1155/2018/7012710. 